as the smaller premium reserved for the first year's assurance is in any measure in excess of the value of the risk run by the company during that year, but it is, to say the least, disingenuous to adopt the popular definition and to describe such a valuation as a "net premium" one.

I am, Sir,

Your most obedient servant,

London.

H. AMBROSE SMITH.

** As the latter part of the above letter deals to some extent with the same subject as Mr. McCandlish's paper, published in the last number of the Journal, Mr. Smith wishes us to mention that it was in type before he had heard of Mr. MeCandlish's essay.--ED. J.I. A.

\title{
MR. DEUCHAR'S PAPER ON NEGATIVE POLICY-VALUES.
}

\section{To the Editor of the Journal of the Institute of Actuaries.}

SrR,-The question discussed by Mr. W. T. Gray, in his interesting letter in the Oct. Number of the Journal (p. 73), is one of importance. $\mathrm{He}$ has shown by figures that, at any rate in one particular case, it is a matter of indifference to a company which so treats its policies as to convert many of them into assets instead of liabilities, whether it value at long or short intervals of time. But an arithmetical demonstration, however useful in illustration of one more general, is not altogether satisfactory by itself; and on this account, as well as because Mr. Gray appears to have fallen in one respect into a little confusion, I venture to trouble you with a brief mathematical proof.

Let us suppose two companies, A and B, identical, to start with, in every respect, doing an identical amount and description of business, and making the same rate of interest, say $i$, on their funds; and let them value on the same basis, and so that all policies have negative values for $t$ years. Let, however, A divide its profits annually, and B septennially. At the beginning of any given septennium, the two companies will be identical in position. At the end of the first year of that septennium $A$ will distribute a certain surplus, say $m_{1}$; at the end of the second year another, $m_{2}$; and so on; and at the end of the seventh year, $m_{7}$. At the end of the first year let $B$ also make a valuation for the private information of its manager, but let it retain in hand the discovered surplus, which will also be $m_{1}$, and carry it to a separate account in its ledger. Except for a book entry, it is precisely as it would have been had it not made an investigation, and its life funds proper are of the same amount as those of $\mathbf{A}$ at the same instant of time, only they are supplemented by the sum $m_{1}$ in the suspense account. At the end of the second year let the same process be repeated. In addition to the first surplus, now grown to $m_{1}(1+i)$, it brings out another, which must be $m_{2}$, and treats it in a similar manner, and so on to the end of the septennium, when the total surplus-now to be distributed-in its funds will be-

$$
m_{1}(1+i)^{6}+m_{2}(1+i)^{5}+\ldots .+m_{6}(1+i)+m_{7},
$$

or exactly equal to the profits declared by $A$, accumulated at interest. 
All through the septennium, B, so far as the outside world is concerned, has been an office valuing every seven years, although it has made an annual calculation of which none but its own staff were cognisant, and opened a suspense account in its ledger. But it has not any superiority of position, either as regards reserves or profits, over A, which would not have arisen under the most rigid system of valuation, bringing out the largest possible reserve for every policy, young or old. In fact, after the supposition at the outset of negative values, it has been unnecessary to make mention of them throughout the argument, and the supposition might have been entirely omitted. It is true that, during the currency of the septennium, the financial position of A remained stationary, while that of $B$ was gradually strengthening through the accumulation of undivided profits; but this was not by virtue of negative policy values. A similar result would have appeared with any system of valuation, and would have been the more marked the severer the test applied.

It will be observed that we have not made any supposition as to the nature of the business transacted by the companies. We have only stipulated that an amount equal to the profits divided at the end of each year by A, be immediately and specially invested by B, and allowed to accumulate at compound interest to the end of the septennium: and the result is, that the amount which $B$ then has available for distribution is exactly equal to the profits declared by A, accumulated at interest. With this result Mr. Gray's figures do not, at first sight, quite coincide, for he finds that the profits of A, accumulated at interest, fall short of the available surplus of $\mathrm{B}$ : and his conclusion, which the above reasoning shows to be erroneous, he attempts to justify by algebra, in a way which is easily proved to be fallacious. He says, speaking of the second septennium of the two companies:-

"The amount that $A$ divides at the end of the 8th year is retained " by B, and forms part of those funds whose average amount at the "beginning and end of the year is invested at $4 \frac{1}{2}$ per-cent, so that if " $m$ be the amount distributed by $A$, and $n$ its amount at the end of " the year, $i$ being the rate of interest, we have-

" whence

$$
\begin{aligned}
& \text { “ } \frac{m+n}{2} \times i=n-m, \\
& \text { " } n\left(1-\frac{i}{2}\right)=m\left(1+\frac{i}{2}\right), \\
& n=m \frac{1+\frac{i}{2}}{1-\frac{i}{2}} .
\end{aligned}
$$

"If $i=\cdot 045$,

"we have $n=m \times 1.046036$; so that the amounts divided by A must " be invested at 4.6036 per-cent to amount to the sum now divided " by $\mathrm{B}$, since that is the rate $\mathrm{B}$ has made on these sums it has hitherto " retained."

But surely it is self-evident that the equation from which Mr. Gray starts to find $n$, is not a legitimate one; and it naturally leads to a 
reductio ad absurdum, for $n$, the amount of $m$ at the end of the year, comes out actually greater than $m(1+i)$ a result which no manipulation of investments could possibly produce. It would seem that he has confounded the fixed quantity, $m$, with the fluctuating funds of the company, and made an unnecessary attempt to find its amount at the end of the year; an attempt which has led him to change the rate of interest, $4-5$ per-cent, with which he started, to 4.6036 per-cent. This changed rate of interest he has then employed for the accumulation of the funds of the two companies. It therefore, instead of the original 4.5 per-cent, becomes the rate symbolically written $i$, and on its basis he has correctly worked out the successive positions of the two companies, and proved that if they both realize that rate on their funds, the profits divided annually by $\mathrm{A}$, if accumulated at that rate to the end of the septennium, will exactly equal the sum then available for division by $\mathrm{B}$. The same conclusion would have been arrived at had he adhered in his calculations to the rate, 4.5 per-cent, which he at first selected; but it only introduces confusion to go back for comparison to the rate 4.5 per-cent, when the figures have been worked out at 4.6036 per-cent.

I am, Sir,

Your obedient servant,

1 Bartholomew Lane,

London, E.C.

GEORGE KING.

** Mr. Gray, to whom we forwarded a copy of the above letter, requests us to insert the following reply.-ED. J.I.A.

To the Editor of the Journal of the Institute of Actuaries.

Sir,-The only pint of difference between Mr. King and myself on this subject appears to turn on the question of "two offices making the same rate of interest on their funds."

Mr. King, in his mathematical demonstration, very conveniently assumes the rate $i$, which he applies to A's surpluses alone, and leaves out of consideration the actual working of the funds of the two companies. The only practical answer to the question that $I$ have hitherto come across is in Messrs. Malcolm \& Hamilton's Report to the Board of Trade, where the rate realized by the various offices is obtained by taking the mean amount of the assurance fund at the beginning and end of the year, and dividing it into the total amount of interest received. This method of obtaining the rate is well adapted to the working of a model office; for it at once solves the difficulty attending the daily fluctuation of the assurance fund, from premiums and interest received, and claims, surrenders, and expenses, paid away. It was for these two reasons that I adopted the rate as given in the letter to which Mr. King refers; but it is evident that, as the funds at the end of the year are made up, inter alia, of interest received during the year, the rate quoted ( $4 \frac{1}{2}$ per-cent) can only be a nominal rate, and must not be confounded with a rate of $4 \frac{1}{2}$ per-cent on the amount at the beginning of the year. Each time I referred to 
it, I stated the conditions attending its use; but these $\mathrm{Mr}$. King has disregarded throughout, and, as a necessary consequence, has been led to the conclusion that the equation he quotes is not a legitimate one, and further that I have used two different rates of interest.

In speaking of the accumulation of the annual surpluses at $4 \frac{1}{2}$ percent, $I$ had in mind the ordinary formula for that purpose (in fact the one used by Mr. King), $m(1+i)^{t}$; but it is clear that this formula is inapplicable to a nominal rate of interest, and that it must be replaced by its equivalent effective rate, payable annually at the end of the year, if that formula be employed. The accumulation however might equally well be made, without the intervention of the

effective rate, by means of the formula $m\left(\frac{1+\frac{i}{2}}{1-\frac{i}{2}}\right)^{t}, i$ being the nominal rate previously assumed.

It would seem that Mr. King is of opinion that a book entry with reference to the annual surpluses, would have the effect of separating them from the fluctuating funds of office B; but this I cannot admit, unless special securities be set aside for the purpose, in which case the accumulation would depend on the rate realized by these particular securities, and not on the "disputed" common rate realized by both offices on all their funds.

Thanking you for your courtesy in allowing me this early opportunity of replying to Mr. King's remarks,

I am, Sir,

Your very obedient Servant,

5 Whitehall, S.W.

W. T. GRAY. 